\title{
ПРОВОДНОЙ ШПД: закат после рассвета?
}

А.Голышко, к.т.н., системный аналитик ГК "Техносерв" / race07@inbox.ru, В.Шуб, к.ф.-м.н., заместитель руководителя ЦК НТИ БСИВ при Сколтехе

DOI: $10.22184 / 2070-8963.2020 .86 .1 .56 .58$

Каких-то двадцать лет назад участники рынка широкополосного доступа В2С мечтали об оптике хотя бы до дома, а сам рынок развивался преимущественно там, где были самые большие деньги - то есть в В2В. Беспроводной доступ с первыми сетями IEEE 802.11 еще не был конкурентом никому, а передача данных по сетям GSM - даже "телефонному" доступу dial-up.

Редко приходится слышать, что кто-то съел слишком мало. Томас Джефферсон (1743-1826), президент США

Стремительное развитие технологий и победное шествие интернета, на который "повесили" сегодня чуть ли не всю мировую экономику, серьезно изменили баланс в телекоммуникациях, и теперь протянуть оптику до квартиры - обычное дело. Ну а пока ее прокладывали, сети мобильной связи "подставляли плечо" и брали на себя часть нагрузки "тех, кому очень надо". Так было в регионах и с сетями 3G, и с сетями 4G, пока абонентов было относительно немного. Однако когда абонентская база вырастала, а проводной ШПд наращивал инфраструктуру, он забирал эту нагрузку обратно.

Как указано в материалах нацпроекта "Цифровая экономика", в 2019 году доля домохозяйств, имеющих широкополосный доступ к интернету, должна составить 79\%, в 2021 году - 89\% и в 2024 году - 97\%. Также к интернету к концу 2019 года обещано подключение 13958 населенных пунктов с количеством жителей от 250 до 500 человек. Кроме того, в 2021 году в десяти российских городах-миллионниках должны быть созданы сети связи $5 \mathrm{G}$.

Ну а сейчас ландшафт проводного ШПд в России выглядит так:

- проникновение - порядка 2/3 от общего количества или около 56 млн домохозяйств;

- ARPU - суммарно порядка 5-7 долл. США;

- консолидация - порядка 2/3 абонентской базы с олигополией "большой пятерки";
- применяемые технологии: FTTB (+HFC), FTTH (GPON, P2P), HFC/DOCSiS, xDSL;

- сервисы - непосредственно ШПД, (CA/IP)TV, triple/quad-play;

- скорости передачи к/от абонента - до 1Гбит/с;

- задержки сигнала (RTT) - не нормируются по SLA.

Поскольку в настоящее время просвещенное человечество находится в горячем ожидании сетей 5G, стоит напомнить, что, как и в случае сетей 4G, пользователи получат лишь две основные услуги связи - еще большие скорости передачи данных и еще меньшие задержки при этой передаче. Все остальные услуги, часто муссируемые в СМИ, должны придумать те, кто обычно их и придумывает, а телекоммуникационные службы смогут реализовать все это проще и, возможно, дешевле. Разумеется, сети 5G должны обеспечивать ряд дополнительных опций, позволяющих за счет технологических ухищрений (еMBB, uRLLC, mMTC) предоставлять указанное выше гораздо большему количеству пользователей, в том числе сгруппированному в виде виртуальных операторов. В целом специфика сетей связи 5G (Release 15 3GPP) выглядит так:

- скорости передачи к абоненту - до 20 Гбит/с на соту/сектор;

- скорости передачи от абонента - до 10 Гбит/с на соту/сектор;

- задержки сигнала (RTT) - от 1 до 10 мс; 
- ширина несущих - до 100 МГц;

- спектральная эффективность - до 50 бит/с/Гц;

- спектральный диапазон - от 700 МГц до 90 ГГц;

- плотность объектов IоT - до 1 млн штук на соту. Формирование потребительской стоимости ШПД/5G происходит за счет того, что, к примеру, еMBB - это любой видеоконтент в 4K и 8K, AR/VR; uRLLC - это гейминг, опять же AR/VR, гарантированные мониторинг и управление в реальном времени всем, что движется и не движется, a mMTC - интернет машин (то есть без людей). Будет поддерживаться и новый парк абонентских устройств: домашние роутеры 5G/Wi-Fi 6; телевизоры 8K с модемами 5G; камерафоны с сенсорами 108 Мп и выше; приставки AR/VR с разрешением 2K/4K/8K NeuraLace; объекты умного дома и, разумеется, IоT, ради которого во многом и разрабатывались сетевые решения 5G.

Соответственно, ожидаемый объем сервисов и сопутствующие нагрузки на сети 5G будут выглядеть примерно так:

- стриминг DL 4K - десятки Мбит/с на сессию;

- стриминг DL 8K - до 100 Мбит/с и выше на сессию;

- загрузка UL 4K/8K - до 100 Мбит/с на сессию;

- машинное зрение - разрешение UHD/S-UHD+;

- игры и управление удаленными объектами - RTT менее 10 мс.

Что можно ожидать с точки зрения потребительской ценности сервисов мобильной связи 5С? Прежде всего, это может быть стандартное пакетное предложение услуги сотовой связи - "Х минут голос + Y минут SMS + Z гигабайт трафика данных". При средней скорости передачи данных UL/DL в сетях 5G порядка 100+ Мбит/с тариф с месячным лимитом 10-50 Гб - это составит лишь несколько минут передачи данных в месяц. По объему трафика с голосовыми минутами все еще хуже. Аналогично будет обстоять дело и с SMS/ RCS. Очевидный выход для абонента - предоставление безлимитного тарифа по трафику данных плюс tethering (использование мобильного телефона в качестве точки доступа других устройств к услугам сети передачи данных оператора сотовой связи) - это не что иное, как прямая конкуренция ПшПд.

Теперь рассмотрим потенциальные драйверы ARPU в сетях 5G. Потенциальная структура персонального тарифа - безлимитный трафик данных + tethering + VAS. В части еMBВ - замещение вещательного ЦЭТВ, IPTV Broadcast и (S)VoD на модель ОТТ с проникновением до 100\%. В части uRLLC - gaming + AR/VR - комбинированная плата за объем трафика и гарантированно низкую задержку с проникновением примерно 10-20\%. В части mMTC - IоT - "Умный Дом" и т.п. с проникновением порядка 10\%. В части B2B/G - частные корпоративные сети или фрагменты сетей c "микроядром" для реализации функций еММB, URLLC и тMTC.

Новая сетевая архитектура ШПД 5G - это фактически полная интеграция 5С и ПшПд:

- RTT 1-10 мс требует максимального приближения узлов пакетной коммутации к радиоголовкам с последующей интеграцией - Mobile Edge Computing (MEC);

- 10+ Гбит/с на БС/радиоголовку потребует когерентных оптических транспортных систем во фронтхоле;

- вся опорная сеть FMC в пределе - когерентная DWDM Nx100 Гбит/c;

- интеграция СХД в радиоголовки и портирование узлов CDN в них (иначе это "плоская" CDN);

- оптоволоконные выносные домашние/офисные, пико/аттосоты с MEC, обеспечивающие RTT, а также интеграция с хот-спотами Wi-Fi 6. Что будет с FWA (Fixed Wireless Access)?

Очевидно, в миллиметровом диапазоне длин волн произойдет очередной "подход к снаряду". Тем более, что есть прецедент - начавшееся в США развертывание сетей фиксированного радиодоступа в миллиметровом диапазоне. Впрочем, все предыдущие попытки коммерциализации FWA проваливались во всех частотных диапазонах: NMT-450, AMPS, CDMA 800, WiMAX и др. Успех если и был, то кратковременный, пока сеть не загружена и конкуренты далеко. Причины проблем понятны заранее - это низкое проникновение услуги, неконкурентоспособность с ПШПД, необходимость использования outdoor СРЕ. В свою очередь, использование систем РМР 5G миллиметрового диапазона LoS теоретически возможно для создания кластеров outdoor СРЕ в сельской местности, однако ограничения и проблемы - все те же.

Потенциальные бизнес-модели в ШПД 5G:

- SLA и тарифицирование по нескольким параметрам QoS - объем (безлимитного) трафика, пиковые скорости передачи, минимальные и максимальные задержки сигнала для резидентских и корпоративных клиентов;

- возможный компромисс для кампусных сетей - работа на частотных присвоениях в миллиметровом диапазоне (?);

- выделение независимых виртуальных доменов для резидентных, корпоративных 
и правительственных абонентов с разными SLA;

- создание "зонтичных" проводных широкополосных операторов транспортной инфраструктуры;

- новый виток конкуренции 5G с проводным ШПД - дальнейшее замещение проводного сегмента в последних 100-1000 м с одновременным сращиванием сетей на транспортном уровне. Так к чему мы придем в эпоху 5С, если онатаки когда-нибудь наступит?

Массовое развертывание сетей 5G приведет к дальнейшей каннибализации сегмента проводного ШПД и ЦЭТВ. Иначе - там, где будет покрытие 5G, вообще-то, не будет необходимости ни в том ни в другом. Зато новые конкурентные преимущества 5G - нормированная задержка сигнала в URLLC, возможность сверхширокополосного вещания в еМВВ - могут стать весьма интересными для различных групп пользователей. Дальнейшее развитие FMC потребует радикальной сквозной модернизации и умощнения всего оптоволоконного транспортного уровня интегрированных сетей, превращая всю сетевую инфраструктуру 5G попросту в мощную и разветвленную оптоволоконную сеть с радиоокончаниями на последних 100/10 м. Соответственно коммерциализация домашних пико/аттосот 5G может также каннибализировать и те самые"последние 10-100 M" Wi-Fi 6/7.

Не является ли 5С с дальнейшим развитием 6G лишь способом еще больше заменить радиодоступ оптоволокном? Приз понятен - извлечение денег из каждой страны на новую инфраструктуру, отсутствие которой будет рассматриваться как серьезный риск (авто с недостаточным интеллектом столкнутся, роботы свихнутся, а беспилотные дроны падут на наши головы).

Останется ли ниша для тех, с кем мы имеем дело сегодня, когда затянем в плотные сети оптоволоконных кабелей нашу планету? Очевидно, они будут другими, и другие станут вместо них. Другими станем и мы.

\section{"Роскосмос" вывел на орбиту 34 спутника глобальной сети OneWeb}

Спутники связи британской компании OneWeb, запущенные российской ракетой-носителем с космодрома "Байконур", успешно выведены на орбиту, сообщил "Роскосмос" . "Получено подтверждение успешного отделения всех 34 спутников связи OneWeb от разгонного блока "Фрегат"! Они выведены на целевые орбиты", - говорится в посте госкорпорации в Twitter.

Ракета "Союз" стартовала в 00:42 мск 7 февраля с 31-й площадки Байконура. В 00:52 мск "Фрегат" с космическими аппаратами отделился от третьей ступени ракеты на суборбитальной траектории. Выведение спутников на целевую круговую орбиту высотой 450 км было обеспече- но за счет двух включений двигателя "Фрегата". Аппараты OneWeb отделялись от "Фрегата" группами по два или четыре спутника. Низкоорбитальные космические аппараты OneWeb предназначены для обеспечения наземных потребителей высокоскоростным интернетом напрямую через спутниковую связь. Орбитальная группировка будет состоять из 18 плоскостей по 36 аппаратов в каждой. В общей сложности компания намеревается развернуть на околоземной орбите около 600 спутников и начать их коммерческое использование в 2020 году. K 2021 году OneWeb намерена обеспечить 24-часовое покрытие связью всей Земли. В июне 2015 года компании Arianespace и OneWeb подписали контракт на 21 пуск ракет-носителей "Союз" с разгонными блоками "Фрегат" для выведения в космос 672 спутников OneWeb. С космодрома "Байконур" намечается девять пусков, с "Восточного" - шесть, с "Куру" (Гвиана) - шесть. Первые шесть спутников OneWeb были запущены из Гвианского космического центра с помощью ракеты-носителя "Союз-СТ-Б" и разгонного блока "Фрегат-М" 28 февраля 2019 года.

По информащии корпоращии "Роскосмос"

\section{"Ростелеком" открыл контактный центр В2О}

В феврале 2020 года "Ростелеком" открыл в Липецке федеральный центр для операторов связи. В сервисные функции центра при обслуживании зарубежных и российских компаний входит организация подключений услуг и их дальнейшая поддержка. Основные услуги для операторов связи - это пропуск и присоединение голосового трафика, IР-транзит, аренда каналов, VPN и ряд других.
"Мы сравнили доступность, стоимость и кадровый ресурспо всей России, посмотрели на поддержкуруководителей Липецкого филиала и поняли, что это то место, где стоит сделать федеральный центр и развивать его. Еще в 2016 году мы запустили проект "Единое окно для обращений операторов связи" на базе контакт-центрав Липецке. На сегодняшний день функционал площадки расширился, что потребовало создания новых рабочих мест, специфика которых предполага- ет в том числе знание технического английского языка", - рассказал директор департамента поддержки продаж ПАО "Ростелеком" Александр Астафьев.

После расширения функционала специалисты центра взаимодействуют с операторами связи при организации услуг, технической поддержке и ремонтно-настроечных работах на сети.

По информации ПАО "Ростелеком" 


\section{ИЗДАТЕЛЬСТВО «ТЕХНОСФЕРА» ПРЕДСТАВЛЯЕТ КНИГУ:}

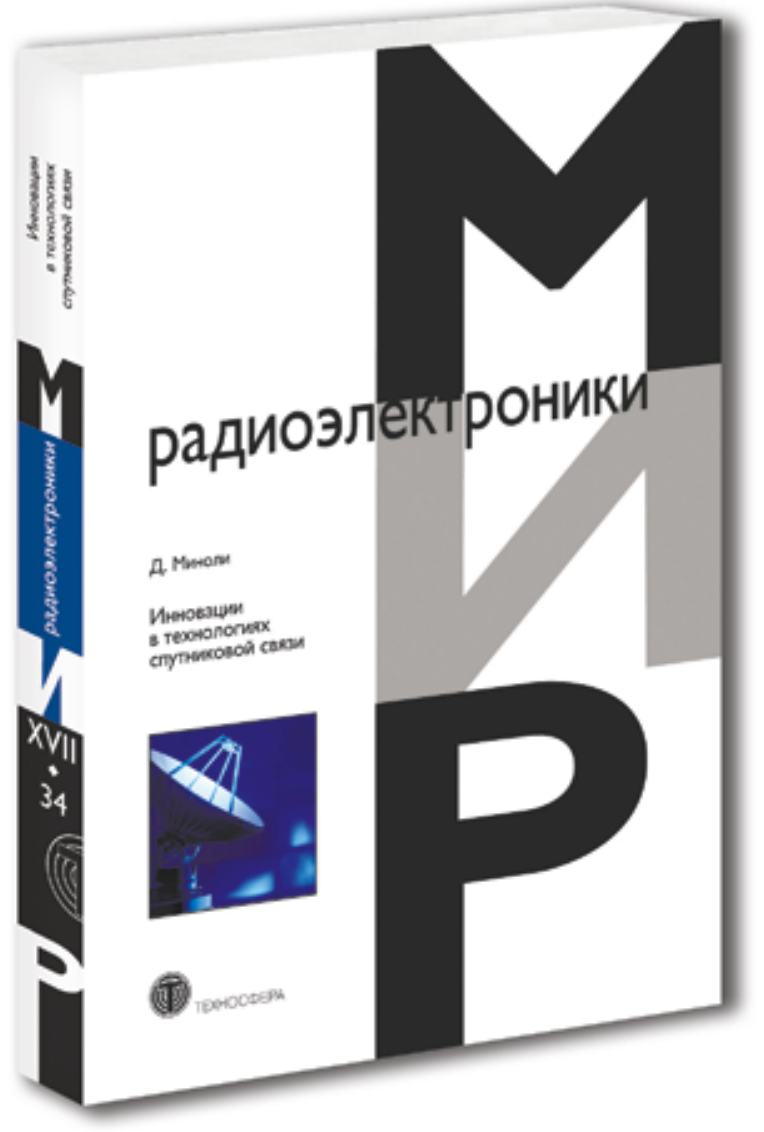

А. Миноли

\section{ИННОВАЦИИ В ТЕХНОАОГИЯХ СПУТНИКОВОЙ СВЯЗИ}

\author{
при поААержке \\ Филиала AO «ОРКК» - «НИИ КП»
}

M.: TEXHOС ФЕPA, 2019. - 446 C.,

ISBN 978-5-94836-545-9

Книга является обзором КАючевых Аостижений в области Коммерческой спутниковой связи. В ней ставится вопрос о том, какими могут быть новые возможности А^я конечных пользовате^ей и поставщиков услуг в использовании новейших быстроразвивающихся инноваций в этой области (расширение специсикации DBV-S2 (DVS-S2X)), технологий спутниковых кана^ов с высокой пропускной способностью (НTS, High throughput satellite), метоАов спутникого применения решений М2M (machine-tomachine) и т. А.).

Книга соАержит 8 глав, перечни источниКов, малоАоступных ряАОвому русскоязычному читателю (исключительно на английском языке), три приложения и преАметный указатель.

Вводная глава содержит справочный технический материал, который может быть полезен инженерам по спутниковой связи вне зависимости от остального соАержания Книги. В частности, в этой главе привеАены свеАения о наименованиях радиодиапазонов, используемых в спутниковой связи, а также околоземных орбит спутников космической связи (не только геостационарных). В приложении В привеАен ГАоссарий основных концепций и терминов спутниковой связи. ОН созАан на основе различных источников в ограниченном объеме инфоормации с привеАением ссылок на эти источники.

ИзАание Можно считать справочным пособием, так Как в ввоАную ГАаву вКАючен справочный технический материал, который будет служить в качестве учебника по спутниковой связи А^я начинающих.

\section{Как заказать наши книги?}

По почте: 125319, Москва, а/я 91

По факсу: (495) 956-33-46

E-mail: knigi@technosphera.ru 